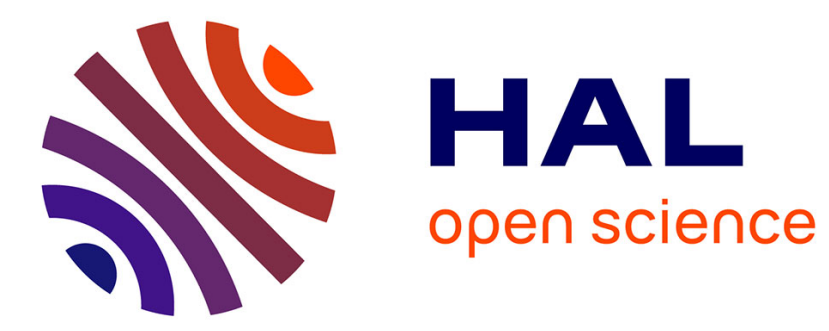

\title{
Quantification of hardening contribution of G-Phase precipitation and spinodal decomposition in aged duplex stainless steel: APT analysis and micro-hardness measurements
}

\author{
R. Badyka, G. Monnet, S. Saillet, C. Domain, C. Pareige
}

\section{- To cite this version:}

R. Badyka, G. Monnet, S. Saillet, C. Domain, C. Pareige. Quantification of hardening contribution of G-Phase precipitation and spinodal decomposition in aged duplex stainless steel: APT analysis and micro-hardness measurements. Journal of Nuclear Materials, 2019, 514, pp.266-275. 10.1016/j.jnucmat.2018.12.002 . hal-02061837

\section{HAL Id: hal-02061837 \\ https://hal.science/hal-02061837}

Submitted on 29 May 2019

HAL is a multi-disciplinary open access archive for the deposit and dissemination of scientific research documents, whether they are published or not. The documents may come from teaching and research institutions in France or abroad, or from public or private research centers.
L'archive ouverte pluridisciplinaire HAL, est destinée au dépôt et à la diffusion de documents scientifiques de niveau recherche, publiés ou non, émanant des établissements d'enseignement et de recherche français ou étrangers, des laboratoires publics ou privés. 


\title{
Quantification of hardening contribution of G-Phase precipitation and spinodal decomposition in aged duplex stainless steel: APT analysis and micro-hardness measurements
}

\author{
R. Badyka ${ }^{a}$, G. Monnet ${ }^{\text {b }}$, S. Saillet ${ }^{\text {b }}$, C. Domain ${ }^{\text {b }}$, C. Pareige ${ }^{\text {a, * }}$ \\ ${ }^{a}$ Groupe de Physique des Matériaux, UMR 6634 CNRS, Université de Rouen Normandie et INSA de Rouen Normandie, France, Avenue de l'université, 76801 , \\ St Etienne du Rouvray, France \\ ${ }^{\mathrm{b}}$ EDF R\&D Département Matériaux et Mécanique des Composants, Avenue des Renardières - Ecuelles, F-77250, Moret sur Loing, France
}

\begin{abstract}
A B S T R A C T
Ageing of cast duplex stainless steels (DSS) is attributed to the decomposition of the ferrite: spinodal decomposition and precipitation of G-phase particles. This leads to an increase in hardness and a decrease in Charpy toughness. According to the literature, spinodal decomposition is accepted to play a major role on the hardening even if the role of G-phase precipitation on mechanical properties is still not clear. This work links microstructural characterization performed using atom probe tomography to micro-hardness of the ferrite for a wide variety of duplex steels (from cast steels with and without Mo to lean steels) aged under different conditions. An attempt to quantify the contribution of both spinodal decomposition and G-phase precipitation is made by applying linear and square superposition principle of Ardell, Orowan and a modified BKS models. The models used are shown to give an excellent estimation of the experimental values of the hardness increase of the ferrite of the cast and lean steels for a wide range of composition and temperature. This work shows that, conversely to what is said in the literature, spinodal decomposition is not systematically the main contributor to hardening.
\end{abstract}

\section{Introduction}

Cast duplex stainless steels (DSS) used in the primary circuit of 2nd generation nuclear power plant endure thermal ageing at service temperature $\left(285^{\circ} \mathrm{C}-323^{\circ} \mathrm{C}\right)$. It has been known for a very long time that these steels are prone to thermal ageing [1,2]. The ageing impacts the mechanical properties (toughness decreases and hardness increases). The evolution of the mechanical properties depends on the DSS composition [3-9]. DSS with Mo, which also contain a bigger amount of nickel to keep a good ratio between

\footnotetext{
* Corresponding author.

E-mail address: cristelle.pareige@univ-rouen.fr (C. Pareige).
}

ferrite and austenite are known to age more [3-5,7,9] than Mo-free steels. The ageing of DSS is attributed to the decomposition of the ferrite: spinodal decomposition into regions enriched in iron $(\alpha)$ and regions enriched in chromium $\left(\alpha^{\prime}\right)$, and precipitation of $G$ phase particles enriched in $\mathrm{Ni}, \mathrm{Si}, \mathrm{Mn}$ and Mo when present. The difference of ageing behavior is due to difference in kinetics of the phase transformations $[5,10]$. The movement of dislocations is modified by the concentration gradient induced by spinodal decomposition on the one hand and by the G-phase precipitation on the other hand. The role of each phase on the hardening is still not clear. There is large agreement in the literature that spinodal decomposition is the main contributor to hardening, but disagreements exist on the role of G-phase particles: some authors show a minor role of G-phase particles [11-13] whereas others 
claim the inverse [14,15]. The aim of this paper is to quantify the relative contribution of spinodal decomposition and G-phase particles on hardness. After presentation of the materials and the experimental techniques, the hardening models used for spinodal decomposition and G-phase precipitation are presented. The method to obtain the parameters needed for each model are explained and discussed. In the last part of the article, the results obtained on Mo-free grade in the framework of this study together with previous results obtained on Mo-bearing grades aged in similar conditions $[5,16]$ are used to explain the differences in hardening evolution. Finally, the models are also applied to lean DSS hardening.

\section{Materials and methods}

\subsection{Materials}

The duplex steels studied in this present work are Mo-free steels and Mo-bearing steels provided by Electricité de France (EDF). These steels were heat treated either at $1050^{\circ} \mathrm{C}$ or $1100^{\circ} \mathrm{C}$ during several hours to fix the ferrite content. Composition and ageing treatment for each alloy are provided in Table 1 together with the volume fraction of ferrite. The ferrite compositions are given in Table 2.

One of the objectives of the surveillance programme carried out by EDF is to follow and anticipate the evolution of the mechanical properties of the components made of these steels and to correlate these properties to the decomposition of the ferrite. Service temperature ranges from $285^{\circ} \mathrm{C}$ to $323^{\circ} \mathrm{C}$. To predict long-term DSS behaviors different ageing temperature was studied between $300^{\circ} \mathrm{C}$ and $400^{\circ} \mathrm{C}$.

In order to compare the different kinetics performed at different temperatures, time-temperature equivalence was applied. Considering that evolution of the microstructure is thermally activated, the following relationship can be used to calculate the equivalent ageing time at $323^{\circ} \mathrm{C}$ (teq $323 \mathrm{C}$ ) from the ageing time at temperature $\mathrm{T}\left(\mathrm{t}_{\mathrm{T}}\right)$ :

$t_{e q 323^{\circ} \mathrm{C}}=t_{T} \exp \left[\frac{Q}{R}\left(\frac{1}{596}-\frac{1}{T}\right)\right]$

where: $\mathrm{R}$ is the gas constant, $\mathrm{T}$ is the ageing temperature $(\mathrm{K}), \mathrm{Q}$ is the effective activation energy in the temperature range $\left[323^{\circ} \mathrm{C}\right.$ $400{ }^{\circ} \mathrm{Cl}$. Q have been evaluated to $243 \mathrm{~kJ} / \mathrm{mol}$ in good agreement with [5,10,16-19]. The equivalent ageing time is calculated at $323^{\circ} \mathrm{C}$ because it is the maximum temperature of the cooling system in PWR. The activation energy was calculated considering the wavelength evolution of the spinodal decomposition by comparing value of the wavelength of spinodal decomposition obtained in the ferrite of the steel A-325 with the values obtained in Mo-bearing steels aged at $350{ }^{\circ} \mathrm{C}$ of Table 1 . This is justified by the fact that both G-phase precipitation and spinodal decomposition have the same activation energy in the temperature range $\left[323^{\circ} \mathrm{C}\right.$ $\left.400^{\circ} \mathrm{C}\right][19]$.

It is worth to note that alloy I, is a purely ferritic alloy having the same composition as the ferrite in one of Mo-bearing alloys. B and $\mathrm{G}$ alloys were reannealed at $550{ }^{\circ} \mathrm{C}$ for $2 \mathrm{~h}$ after their initial heat treatment (Table 1). The microstructural characterization of A-350, $\mathrm{B}$ and $\mathrm{C}$ steels aged at $350{ }^{\circ} \mathrm{C}$ were performed by Pareige et al. [5,6] and Novy [16].

\subsection{Methods}

\subsubsection{Microstructural characterization}

APT experiments of the ferrite of D, E, F, G, I and reannealed B alloys were conducted using a local electrode atom probe, LEAP 4000 HR (CAMECA). For the alloys A, B and C ECoTAP and ECoWATAP were used $[5,6]$. During experiments, specimens were cooled down to $40-50 \mathrm{~K}$ in order to mitigate preferential field evaporation of chromium. Atoms were evaporated by applying an electric pulse of $20 \%$ of the DC voltage with a pulse repetition rate of $200 \mathrm{kHz}$ and with a detection rate equal to $0.3 \%$. The detector efficiency is 36\%. The basic principle of APT technique may be found in different books or articles [20-22]. APT samples were prepared either by focus ion beam (FIB) or by standard electro polishing methods from $0.3 \times 0.3 \times 10 \mathrm{~mm}^{3}$ parallelepiped sample. For the latter, two electrolytes were used (75\% acetic acid/25\% perchloric acid solution and a $2 \%$ perchloric acid diluted in 2-butoxyethanol solution). 3D reconstructions were performed using IVAS software (CAMECA) and the data were analyzed using the threedimensional data software for atom probe users developed by GPM Rouen. For reconstruction, an image compression factor equal to 1.5 and a field factor value between 3.6 and 5 (depending on the analyzed sample and on the fact that samples were on microcoupon or not) were used. Field factor values were adjusted so as interplanar distances corresponding to the detected crystallographic directions are correct for each experiment.

To characterize the spinodal decomposition, two parameters were used: the wavelength and the amplitude. The mean wavelength of the spinodal decomposition $(\lambda)$ was estimated using autocorrelation functions calculated from 1D $\mathrm{Cr}$ concentration profiles [23]. The profiles were drawn by extracting volumes of square cross section of $1 \times 1 \mathrm{~nm}^{2}$ from the whole analyzed volume and by moving a $1 \times 1 \times 1 \mathrm{~nm}^{3}$ box along the $z$ axis with a step value of $0.1 \mathrm{~nm}$. The wavelengths were derived from the first two peaks of each auto-correlation profile. The mean wavelengths have

Table 1

Composition of steels in wt \%. Also, the volume fraction of ferrite $(\delta(\%))$, intervals of ageing time and the ageing temperature are given.

\begin{tabular}{|c|c|c|c|c|c|c|c|c|c|c|}
\hline Steel (wt \%) & $\mathrm{Cr}$ & $\mathrm{Ni}$ & $\mathrm{Si}$ & Mo & Mn & $\mathrm{C}$ & $\mathrm{Fe}$ & $\delta(\%)$ & Ageing time intervals $(\mathrm{h})$ & Ageing temperature $\left({ }^{\circ} \mathrm{C}\right)$ \\
\hline A-350 [5,16] (Mo-bearing) & 21.0 & 9.81 & 1.12 & 2.60 & 0.66 & 0.03 & Bal. & 29.5 & $2500-75,000$ & 350 \\
\hline A-325 [5,16] (Mo-bearing) & & & & & & & & & 72,000 & 325 \\
\hline B $[5,16]$ (Mo-bearing) & 20.1 & 11.68 & 1.12 & 2.49 & 0.81 & 0.03 & Bal. & 17 & $100,000-200,000$ & 350 \\
\hline & & & & & & & & & \multicolumn{2}{|c|}{$200,000 \mathrm{~h}$ at $350{ }^{\circ} \mathrm{C}+2 \mathrm{~h}$ at $550^{\circ} \mathrm{C}$} \\
\hline C [6] (Mo-free) & 20.3 & 8.40 & 0.95 & 0.04 & 0.84 & 0.03 & Bal. & 12 & $2500-100,000$ & 350 \\
\hline $\mathrm{D}$ (Mo-bearing) & 20.9 & 10.60 & 1.00 & 2.60 & 0.60 & 0.03 & Bal. & 21 & $90,000-200,000$ & 300 \\
\hline $\mathrm{E}$ (Mo-free) & 19.9 & 8.47 & 0.81 & 0.18 & 0.44 & 0.03 & Bal. & 13.5 & $30,000-200,000$ & 350 \\
\hline $\mathrm{F}$ (Mo-free) & 19.9 & 8.15 & 0.75 & 0.24 & 0.37 & 0.03 & Bal & 13.5 & $30,000-100,000$ & 350 \\
\hline \multirow[t]{2}{*}{ G (Mo-bearing) } & 21.7 & 9.61 & 0.94 & 2.64 & 0.82 & 0.03 & Bal. & 28.5 & 2400 & 400 \\
\hline & & & & & & & & & \multicolumn{2}{|c|}{$2400 \mathrm{~h}$ at $400^{\circ} \mathrm{C}+2 \mathrm{~h}$ at $550^{\circ} \mathrm{C}$} \\
\hline I (ferritic alloy) & 23.5 & 6.24 & 1.39 & 3.72 & 0.46 & I & Bal. & 100 & 10,000 & 400 \\
\hline
\end{tabular}


Table 2

Composition of ferrite in at \% obtained by APT measurement. N.M.: Not measurable.

\begin{tabular}{|c|c|c|c|c|c|c|c|c|}
\hline Ferrite (at \%) & $\mathrm{Cr}$ & $\mathrm{Ni}$ & $\mathrm{Si}$ & Mo & Mn & $\mathrm{C}$ & $\mathrm{Cu}$ & $\mathrm{Fe}$ \\
\hline $\begin{array}{l}\text { A-350 [5,16] (Mo-bearing) } \\
\text { A-325 [5,16] (Mo-bearing) }\end{array}$ & $27.38 \pm 0.12$ & $5.42 \pm 0.06$ & $2.59 \pm 0.04$ & $2.09 \pm 0.04$ & $0.54 \pm 0.02$ & N.M & $0.05 \pm 0.01$ & Bal. \\
\hline В $[5,16]$ (Mo-bearing) & $27.51 \pm 0.11$ & $5.48 \pm 0.06$ & $2.62 \pm 0.04$ & $2.57 \pm 0.04$ & $0.70 \pm 0.02$ & $0.02 \pm 0.01$ & $0.05 \pm 0.01$ & Bal. \\
\hline C [6] (Mo-free) & $26.11 \pm 0.12$ & $3.51 \pm 0.97$ & $2.56 \pm 0.02$ & $0.03 \pm 0.01$ & $0.21 \pm 0.01$ & $0.01 \pm 0.01$ & N.M & Bal. \\
\hline $\mathrm{D}$ (Mo-bearing) & $28.34 \pm 0.11$ & $6.42 \pm 0.06$ & $2.46 \pm 0.04$ & $1.88 \pm 0.03$ & $0.45 \pm 0.02$ & N.M & N.M & Bal. \\
\hline $\mathrm{E}$ (Mo-free) & $25.25 \pm 0.01$ & $4.78 \pm 0.02$ & $1.80 \pm 0.01$ & $0.20 \pm 0.02$ & $0.31 \pm 0.01$ & $0.02 \pm 0.01$ & $0.02 \pm 0.01$ & Bal. \\
\hline $\mathrm{F}$ (Mo-free) & $26.06 \pm 0.03$ & $4.40 \pm 0.03$ & $1.74 \pm 0.01$ & $0.14 \pm 0.02$ & $0.32 \pm 0.01$ & $0.03 \pm 0.01$ & $0.02 \pm 0.01$ & Bal \\
\hline G (Mo-bearing) & $25.98 \pm 0.02$ & $6.19 \pm 0.02$ & $2.27 \pm 0.02$ & $2.09 \pm 0.04$ & $0.74 \pm 0.01$ & $0.04 \pm 0.01$ & $0.04 \pm 0.01$ & Bal. \\
\hline I (ferritic alloy) & $24.96 \pm 0.02$ & $5.86 \pm 0.01$ & $2.73 \pm 0.01$ & $2.14 \pm 0.01$ & $0.46 \pm 0.01$ & N.M & 1 & Bal. \\
\hline
\end{tabular}

been calculated over at least 50 concentration profiles for each APT volume and from at least three different tips for each condition. The uncertainty on the wavelengths is equal to two times the standard deviation calculated over more than 300 values of wavelength per condition.

The method proposed by Zhou et al. [24] using the radial distribution function analysis (RDF) permitted the assignment of composition to $\alpha$ and $\alpha^{\prime}$ zones. The amplitude of spinodal decomposition is defined by $\Delta C r=C_{C r \alpha^{\prime}}-C_{C r \alpha}$, where $C_{C r \alpha^{\prime}}$ and $C_{C r \alpha}$ are the $\mathrm{Cr}$ concentration in $\alpha$ and $\alpha$ zones respectively.

Regarding G-phase precipitation, the radius of the particles and the number density were calculated for each analysis. To isolate Gphase particles from $\alpha$ and $\alpha^{\prime}$ zones, the iso-position filter [6,21,25] was applied using the concentration threshold $\mathrm{X}_{\mathrm{Ni}+\mathrm{Si}+\mathrm{Mn}+\mathrm{Mo}}>15 \%$. The threshold corresponds to the value for which the concentration histogram of the randomized data set of same composition is negligible $(<0.01 \%)$ [25]. Fe shells are sometimes observed around particles after applying the iso-position filter. These shells were removed using an erosion method. Once the Fe shells were removed, the particle radius $\left(R_{G}\right)$ of each individual particle was calculated. For more information on the atom-probe characterization procedure, refer to Lefebvre et al. [21]. The number density of the G-phase particles was determined by the ratio of the number of the observed precipitates to the overall analyzed volume.

The in-core composition of the G-phase particles is obtained from the plateau observed on the erosion profiles.

\subsubsection{Mechanical characterization}

Mechanical tests were performed by micro-hardness measurements using the procedure implemented by EDF. For each sample, thirty measurements were performed in ferrite grains with Vickers indenter with a load of $50 \mathrm{~g}$ and a dwell time equals to $15 \mathrm{~s}$. Mean and standard deviation are calculated over the 10 highest values. Three times the standard deviation is subtracted from the mean to define a threshold. Only measurements above this threshold are considered for the final calculation. A minimum of 15 values is mandatory. The final average micro-hardness value $\left(\mathrm{HV}_{0.05}\right)$ and the final standard deviation value are calculated over the selected measurements (the uncertainty is equal to $2 \sigma$ ). With this method, lower hardness values influenced by austenite are excluded.

\subsection{Hardening models and input data}

Because hardening of the ferrite during ageing is due to the development of spinodal decomposition and G-phase precipitation, contributions of the two phase transformations have to be considered.

\subsubsection{Spinodal hardening model}

The movement of dislocations is modified by the development of spinodal decomposition. To estimate the obstacle strength, different hardening models exist [26-29]. Both Cahn and Ardell models [28,29] calculate the critical resolved shear stress $\tau_{C R S S}$ necessary to initiate dislocation slip in the case of a microstructure made of periodic sinusoidal concentration fluctuations as in the case of spinodal decomposition. Concentration amplitude and wavelength of the sinusoids are the two parameters the critical resolved shear stress depends on. The advantage of the Ardell model over the Cahn model is to consider the diffuse character of the spinodal decomposition and the fact that spinodal decomposition is not made of perfect sinusoidal concentration waves. For this reason, the Ardell model has been chosen to account for the hardening from spinodal decomposition. $\tau_{C R S S}^{\alpha / \alpha^{\prime}}$ is given by the following equation:

$\tau_{C R S S}^{\alpha / \alpha^{\prime}}=\beta\left(\left(\Delta C_{C r}\right) \delta Y\right)^{\frac{5}{3}}\left(\frac{b \lambda}{\Gamma}\right)^{2 / 3}$

where: $\beta$ is the obstacle strength, $\Delta C_{C r}$ and $\lambda$ are the amplitude and the wavelength of the spinodal decomposition as measured using APT respectively, $\delta=\frac{a_{\alpha^{\prime}}-a_{\alpha}}{a_{\alpha^{\prime}}}$ is lattice mismatch between $\alpha$ and $\alpha^{\prime}, \mathrm{Y}$ is equal to $Y=\left[\left(C_{11}+2 C_{12}\right)\left(C_{11}-C_{12}\right)\right] / C_{11}$ calculated from the pure iron elastic constants [29], $\mathrm{b}$ is the Burgers vector of edge dislocations in BCC and $\Gamma$ is the line tension of the dislocation. The expression $\Gamma=\frac{1}{2} \mu b^{2}$ was used to estimate $\Gamma$ with $\mu$, the ferrite shear modulus of the matrix given by Ghosh et al. [30]:

$$
\begin{aligned}
\mu(\alpha-F e)= & \left(8.407+\sum x f\left(\frac{d \mu}{d x}\right)\right)\left[1-0.48797\left(\frac{T}{T c}\right)^{2}\right. \\
& \left.+0.12651\left(\frac{T}{T c}\right)^{3}\right] * 10^{10} \mathrm{~N} / \mathrm{m}^{2}
\end{aligned}
$$

where Tc is the Curie temperature of $\alpha$-Fe (1043 K), T temperature, $\mathrm{X}_{\mathrm{f}}$ and $\frac{d \mu}{d x}$ are the concentration of element $\mathrm{x}$ and the variation of the shear modulus relative to the concentration of the solute respectively. $\frac{d \mu}{d x}$ is given in Ghosh et al. paper [30] for the different elements. The shear modulus considered for the calculation is an average of the values obtained for the Mo bearing and Mo-free steels and is equal to $82.9 \mathrm{GPa}$. This value agrees well standard values for ferritic steels $[30,31]$.

In the present study, constants have the following values: $a_{\alpha^{\prime}}=0.2882 \mathrm{~nm}$ and $a_{\alpha}=0.2866 \mathrm{~nm} \quad$ [32], $\quad \mathrm{b}=0.248 \mathrm{~nm}$ and $\Gamma=2.55 .10^{-9} \mathrm{~N}$

\subsubsection{Precipitation hardening}

The G-phase appears as spherical particles [3-6,33]. Precipitation hardening models have thus been used. Two models are considered: the modified Orowan model [34] (called Orowan model in the following) and a modified version of the Bacon, Kocks, and Scattergood model (BKS) [35] proposed by Monnet [36]. 
The critical resolved shear stress as given by the modified Orowan model [34] is expressed by equation (4). This simple model is based on the distribution of shearable obstacles over a periodic array.

$\tau_{\text {CRSS }}^{G-\text { phase }}=\alpha_{G} \mu b \sqrt{N_{G} d_{G}}$

where $\alpha_{\mathrm{G}}$ is the strength of $\mathrm{G}$ phase particles, $\mathrm{N}_{\mathrm{G}}$ and $\mathrm{d}_{\mathrm{G}}$ are number density and diameter of the particles respectively.

Unlike the Orowan model, the BKS dispersed barrier model [35] considers a random array of non-shearable obstacles and dislocation self-stress. Recently a modified version of the BKS model was proposed by Monnet [36] to account for the finite strength of the obstacles (shearable precipitates). This model has been shown to reproduce properly precipitation hardening as a function of the shear resistance of both nanometer shearable and non-shearable particles including temperature effect in $\mathrm{Fe}-\mathrm{Cr}$ alloys [36]. The shear stress given by the modified BKS model is expressed as:

$\tau_{\text {CRSS }}^{G-\text { phase }}=\frac{\mu b}{2 \pi l}\left[\frac{\tau_{\text {eff }}}{\tau_{\infty}} \frac{\ln \left(2 \frac{D}{\bar{b}}\right)}{\ln \left(\frac{l}{b}\right)}\right]^{\frac{3}{2}} \ln \left(\frac{l}{b}\right)$

where: $l=\frac{1}{\sqrt{N_{G} d_{G}}}-d_{G}, D=\frac{d_{G} l}{d_{G}+l}$, and $\tau_{\infty}=4500 \mathrm{MPa}$ [36].

In this relationship, the obstacle strength is given by $\tau_{\text {eff }}$ in MPa. This value can be compared to $\alpha_{\mathrm{G}}$ as: $\alpha_{G}=\left[\frac{\tau_{\text {eff }}}{\tau_{\infty}}\right]^{\frac{3}{2}}$

\subsubsection{Superposition principles}

Finally, to calculate the total critical shear stress of the ferrite after ageing, contributions of both spinodal decomposition and Gphase precipitation hardening were added. In most of the cases, linear and square superposition of the contributions are used i.e. $\tau_{\text {tot }}=\left[\sum \tau_{j}^{k}\right]^{1 / k}$ with $k$ equal to 1 for linear, or 2 for square superposition [37]. Both $\mathrm{k}$ values are studied and compared in the following.

The ferrite yield stress increase, $\Delta \mathrm{Re}$, is then deduced according to the following relationship:

$\Delta R e=M \times \tau_{C R S S}$

with M the Taylor factor equal to 2.73 for polycrystalline materials [38]. Conversion of the ferrite yield stress increase into ferrite hardness increase is performed owing to the equation given by Pavlina and Van Tyne [39]:

$\Delta H V=\frac{\Delta R e}{2.876}$

\section{Results}

\subsection{Micro-hardness measurements}

The ferrite hardness of un-aged steels is given in Table 3 for each alloy. In the following, only micro-hardness increase of the ferrite, $\Delta \mathrm{HV}_{0.05}$, will be considered. It is defined by $\Delta \mathrm{HV}_{0.05}=\mathrm{HV}_{0.05}(\mathrm{t})-$ $\mathrm{HV}_{0.05}(\mathrm{t}=0)$. The alloy $\mathrm{D}$ is not added to the plot because the activation energy for time-temperature equivalence between 300 and $323^{\circ} \mathrm{C}$ is not determined.

Fig. 1 reports the ferrite hardness increase with ageing time. In good agreement with the literature, two mechanical behaviors are evidenced depending on the composition [3,4,7]: the Mo bearing steels harden more than Mo-free steels. One can nevertheless note two exceptions: i) G alloy which is a Mo-bearing steel does not have the same hardness evolution than the other Mo-bearing steels. Rather, G alloy behaves as Mo-free steels. ii) the ferritic alloy I hardens like Mo-free steels whereas its ferrite composition is similar to the composition of the ferrite of Mo-bearing steels.

At low equivalent ageing time, $\Delta \mathrm{HV}_{0.05}$ difference between Mobearing and Mo-free steels is already large and equals $150 \mathrm{HV}_{0.05}$. This difference in hardness increase rises with ageing time up to about $250 \mathrm{HV}_{0.05}$ and becomes nearly constant after about $200,000 \mathrm{~h}$ of equivalent ageing time at $323^{\circ} \mathrm{C}$.

In order to understand the gap in hardness increase between Mo-bearing and Mo-free alloys and the behavior of alloys G and I, the microstructural evolution of the ferrite of these alloys has been investigated using APT, and the contributions of both spinodal decomposition and G-phase precipitation to hardening were estimated from the microstructural characterization.

\subsection{Atom probe characterization}

Characteristics of spinodal decomposition and G-phase precipitation as determined using APT are reported in Fig. 2 and Table 3. Fig. $2 \mathrm{a}$ and $\mathrm{b}$ presents the evolution of the wavelength and amplitude of the spinodal decomposition as a function of the equivalent ageing time at $323^{\circ} \mathrm{C}$. Time evolution of particle radius and number density of G-phase particles is shown in Fig. $2 \mathrm{c}$ and $\mathrm{d}$ respectively. In good agreement with the literature [5,6,16], the intensity of G-phase precipitation is much higher in Mo-bearing steels as they contain more G-forming elements (mainly Ni and Mo). It is worth noting that the main difference between Mo-bearing and Mo-free grades relies on the number density of G-phase particles. Indeed, it is not easy to clearly distinguish two behaviors based on the characteristics of spinodal decomposition even if a careful study of the data reveals that lower bound values of wavelength and amplitude correspond to Mo-free steels (blue dash line, Fig. 2a) and higher bounds to Mobearing steels (green dash line, Fig. 2a). Likewise, radius of Gphase particles are very similar in Mo-free and Mo-bearing grades after an initial ageing at $300^{\circ} \mathrm{C}-350^{\circ} \mathrm{C}$. One can thus expect that conversely to what is said in the literature by some authors $[3,14,15]$, G-phase precipitation does not have a minor influence on hardening.

Depending on the ageing conditions, the microstructure of the ferrite may involve only spinodal decomposition, only G-phase precipitation or the two of them as reported in Table 3. Accordingly, three groups of alloys have been identified: one group for alloys with both spinodal decomposition and G-phase precipitation (named I-SG), a second group for which only G-phase particles are observed (II-G) and the last group which corresponds to alloys being only spinodal decomposed (III-S). II-G group is constituted of alloys which have been reannealed at $550^{\circ} \mathrm{C}$ for $2 \mathrm{~h}$ after an initial ageing at $350^{\circ} \mathrm{C}$ or $400^{\circ} \mathrm{C}$ (see Table 1). During this reannealing treatment performed at a temperature above the $\alpha / \alpha^{\prime}$ miscibility gap, the spinodal decomposition dissolved. III-S group is made of $F$ and I alloys. The fully ferritic steel (I alloy) does not present any Gphase precipitation whatever the ageing time. In case of $\mathrm{F}$ alloy, no G-phase particles were observed after $30,000 \mathrm{~h}$ at $350^{\circ} \mathrm{C}$. For longer ageing time, F alloy enters group I-SG. The reason of the kinetics delay is not discussed in this paper.

Table 3 summarizes the characteristics obtained by APT for each alloys and the group they belong to.

\section{Correlation between microstructure and hardening}

\subsection{Determination of obstacle strengths - fitting of superposition models}

Four versions of the superposition principle have been applied 
Table 3

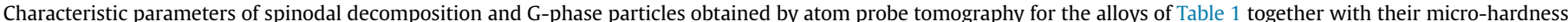

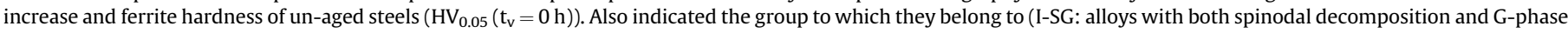
precipitation, II-G: alloys with only G-phase particles, III-S: alloys with only spinodal decomposition).

\begin{tabular}{|c|c|c|c|c|c|c|c|c|c|}
\hline Alloy & Group & Ageing $\left(\mathrm{h}\right.$ and ${ }^{\circ} \mathrm{C}$ ) & $\Delta \mathrm{Cr}$ (\%at) & $\lambda(\mathrm{nm})$ & Number density $\left(\mathrm{x} 10^{23} \mathrm{~m}^{-3}\right)$ & Particle radius (nm) & $\mathrm{C}_{\mathrm{Ni}+\mathrm{Mn}+\mathrm{Si}+\mathrm{Mo}}$ (\%at) in ferrite & $\Delta \mathrm{HV} \alpha_{0.05}$ & $\mathrm{HV}_{0.05}\left(\mathrm{t}_{\mathrm{v}}=0 \mathrm{~h}\right)$ \\
\hline A-325 & $I-S G$ & 72,000 h at $325^{\circ} \mathrm{C}$ & $26.8 \pm 1.0$ & $4.1 \pm 1.0$ & $69.0 \pm 3$ & $1.0 \pm 0.2$ & 10.7 & $371 \pm 25$ & $308 \pm 18$ \\
\hline $\mathrm{D}$ & $I-S G$ & $90,000 \mathrm{~h}$ at $300^{\circ} \mathrm{C}$ & $41.3 \pm 0.4$ & $3.5 \pm 0.8$ & $60.0 \pm 3$ & $0.9 \pm 0.2$ & 12.5 & $327 \pm 85$ & $274 \pm 25$ \\
\hline $\mathrm{D}$ & $I-S G$ & 200,000 h at $300^{\circ} \mathrm{C}$ & $43.4 \pm 1.0$ & $3.9 \pm 1.0$ & $62.0 \pm 3$ & $1.1 \pm 0.2$ & 12.5 & $384 \pm 90$ & $274 \pm 25$ \\
\hline E & $I-S G$ & $30,000 \mathrm{~h}$ at $350^{\circ} \mathrm{C}$ & $42.7 \pm 0.3$ & $4.0 \pm 0.9$ & $9.1 \pm 1.0$ & $1.1 \pm 0.6$ & 7 & $173 \pm 58$ & $230 \pm 18$ \\
\hline E & $I-S G$ & $60,000 \mathrm{~h}$ at $350^{\circ} \mathrm{C}$ & $45.2 \pm 0.2$ & $4.0 \pm 0.9$ & $9.9 \pm 1.4$ & $1.4 \pm 0.6$ & 7 & $217 \pm 58$ & $230 \pm 18$ \\
\hline E & $I-S G$ & $200,000 \mathrm{~h}$ at $350^{\circ} \mathrm{C}$ & $51.1 \pm 0.3$ & $5.1 \pm 1.1$ & $9.7 \pm 1.0$ & $1.5 \pm 0.8$ & 7 & $254 \pm 71$ & $230 \pm 18$ \\
\hline $\mathrm{F}$ & $I-S G$ & 60,000 h at $350^{\circ} \mathrm{C}$ & $49.3 \pm 0.2$ & $4.4 \pm 0.8$ & $1.5 \pm 0.4$ & $0.9 \pm 0.4$ & 6 & $183 \pm 48$ & $239 \pm 17$ \\
\hline $\mathrm{F}$ & $I-S G$ & $100,000 \mathrm{~h}$ at $350^{\circ} \mathrm{C}$ & $47.7 \pm 0.4$ & $5.2 \pm 0.8$ & $4.5 \pm 0.8$ & $1.2 \pm 0.6$ & 6 & $213 \pm 45$ & $239 \pm 17$ \\
\hline G & $I-S G$ & $2400 \mathrm{~h}$ at $400^{\circ} \mathrm{C}$ & $51.1 \pm 0.3$ & $5.4 \pm 0.9$ & $9.9 \pm 0.3$ & $3.0 \pm 0.9$ & 12 & $297 \pm 70$ & $300 \pm 17$ \\
\hline B & $I I-G$ & Annealing $2 \mathrm{~h}$ at $550^{\circ} \mathrm{C}$ & 1 & 1 & $2.5 \pm 0.3$ & $1.9 \pm 0.7$ & 11.4 & $23 \pm 77$ & $293 \pm 34$ \\
\hline G & $I I-G$ & Annealing $2 \mathrm{~h}$ at $550^{\circ} \mathrm{C}$ & I & 1 & $4.4 \pm 0.2$ & $2.3 \pm 0.6$ & 12 & $84 \pm 77$ & $300 \pm 17$ \\
\hline $\mathrm{F}$ & III-S & $30,000 \mathrm{~h}$ at $350^{\circ} \mathrm{C}$ & $36.7 \pm 0.3$ & $4.1 \pm 0.8$ & 1 & 1 & 6 & $148 \pm 61$ & $239 \pm 17$ \\
\hline I & III-S & $10,000 \mathrm{~h}$ at $400^{\circ} \mathrm{C}$ & $55.0 \pm 0.2$ & $6.1 \pm 1.3$ & 1 & I & 11 & $245 \pm 43$ & $304 \pm 17$ \\
\hline
\end{tabular}

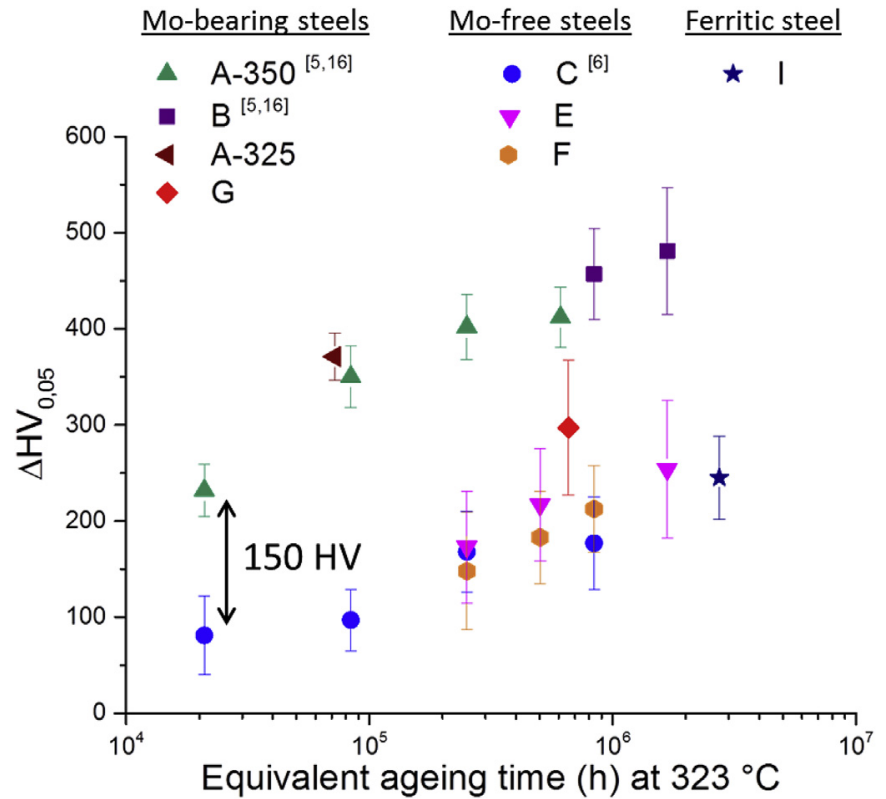

Fig. 1. Hardness increase evolution as a function of equivalent ageing time at $323^{\circ} \mathrm{C}$ of the ferrite of different duplex stainless steels and a ferritic steel (I).

to the alloys:

- Linear superposition of Ardell model for spinodal decomposition and Orowan model for G-phase precipitation (called LAO in the following)

- Linear superposition of Ardell model and modified BKS model for G-phase precipitation (LAB)

- Quadratic superposition of Ardell and Orowan models (QAO)

- Quadratic superposition of Ardell and modified BKS models (QAB)

For every version of the superposition principle, values of the obstacle strength $\beta$ of spinodal decomposition and $\alpha_{\mathrm{G}}$ in case of Orowan model or $\tau_{\text {eff }}$ for modified BKS model, have been obtained by fitting the experimental set of data in the temperature range $\left[323^{\circ} \mathrm{C}-400^{\circ} \mathrm{C}\right]$. The fitting has been undertaken by regression analysis performed with least-squares optimization. Results are provided in Table 4.

One can note the highest obstacle strength of spinodal decomposition. Once determined, these parameters have been used to calculate the micro-hardness increase for each of the conditions of Table 1 . The calculated hardness increases $\left(\Delta \mathrm{HV}_{\text {calc }}\right)$ are compared with the experimental micro-hardness increases $\left(\Delta \mathrm{HV}_{0.05}\right)$ in Fig. 3.

The calculated values of hardness increase, $\Delta \mathrm{HV}_{\text {calc }}$, are very close to experimental values of hardness increase, $\Delta \mathrm{HV}_{0.05}$ for all four of these cases. This is the case whatever the superposition principle used. Comparison of linear and square superposition does not evidence any significant difference. Both linear and square superposition principles give a good estimate of the experimental values. This is also true whatever the ageing temperature of the alloy within the temperature range $\left[300^{\circ} \mathrm{C}-400^{\circ} \mathrm{C}\right]$. Lastly, whatever the group the alloys belong to and whatever they are Mobearing or Mo-free grades, $\Delta \mathrm{HV}_{\text {calc }}$ are very close to experimental values. The models are thus able to provide a good estimate of the micro-hardness increase of the ferrite in every case: when only spinodal decomposition is observed, when only G-phase particles are present or when both spinodal decomposition and G-phase precipitation occur. Nevertheless, one can note higher $\mathrm{R}^{2}$ values when Orowan model is considered to account for G-phase contribution to hardening.

\subsection{Rationalization of the difference in micro-hardness increase} between Mo-bearing and Mo-free steels - quantification of G-phase contribution

In order to understand the difference in micro-hardness evolution between Mo-bearing and Mo-free grades (Fig. 1), we will focus on the ageing kinetics of three steels: A-350, B and C. A-350 and $B$ are Mo-bearing, $C$ is Mo-free. These steels have been aged at $350{ }^{\circ} \mathrm{C}$ for very long time (up to $200,000 \mathrm{~h}$ ) (Table 1 ). As pointed out previously, at the early stages of ageing, the hardness gap between A-350 Mo-bearing and C Mo-free steels is already large and equals $150 \pm 68 \mathrm{HV}_{0.05}$ (Fig. 1).

In Fig. $4 \mathrm{a}$, values of $\Delta \mathrm{HV}_{\text {calc }}$ obtained by LAO superposition principle are compared with the experimental ones. In Fig. 4b, comparison is performed with LAB superposition principle. In both cases, agreement is very good even if linear superposition of Ardell and Orowan models seems to better fit the data at short ageing time for Mo grades. This agrees with the observation made from Fig. 3.

Because no significant difference between linear and square superposition has been observed, only linear superposition will be considered in the following.

Values obtained with the different models at $2500 \mathrm{~h}$ of ageing at $350^{\circ} \mathrm{C}\left(2.10^{4} \mathrm{~h}\right.$ of equivalent ageing time at $\left.323^{\circ} \mathrm{C}\right)$ are reported in Table 5. LAO gives a difference in micro-hardness increase between Mo-bearing and Mo-free steels of $156 \mathrm{HV}_{\text {calc }}$, LAB of $111 \mathrm{HV}_{\text {calc. }}$ LAO value is in excellent agreement with the experimental one (150 

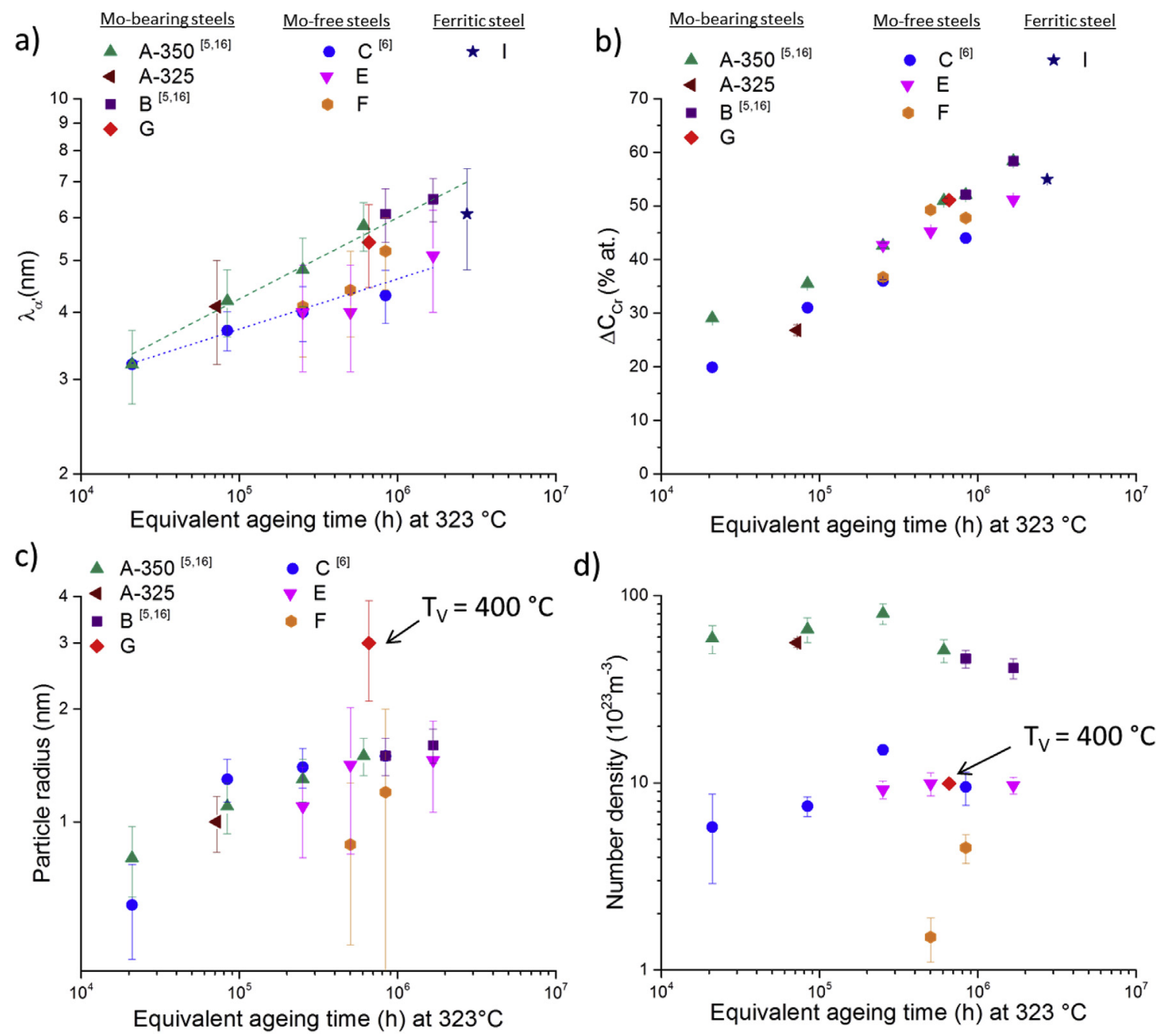

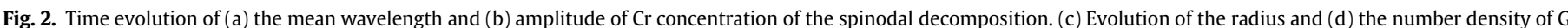

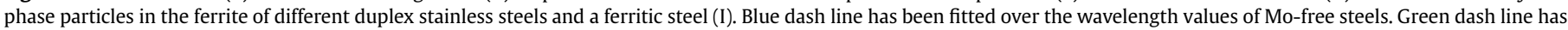

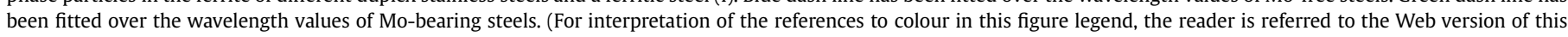
article.)

Table 4

$\beta, \alpha_{\mathrm{G}}$ and $\tau_{\text {eff }}$ obtained by fitting steels data set in the temperature range $\left[323^{\circ} \mathrm{C}-400^{\circ} \mathrm{C}\right]$ using the four superposition principles considered.

\begin{tabular}{|c|c|c|c|c|}
\hline & Superposition principle & Ardell + Orowan & & Ardell + Modified BKS \\
\hline \multirow{4}{*}{$\alpha_{G}$} & Linear $(k=1)$ & $0.63 \pm 0.10$ & \multirow[t]{2}{*}{$\beta$} & $0.65 \pm 0.13$ \\
\hline & Quadratic $(k=2)$ & $0.80 \pm 0.10$ & & $0.75 \pm 0.13$ \\
\hline & Linear $(\mathrm{k}=1)$ & $0.095 \pm 0.020$ & \multirow[t]{2}{*}{$\tau_{\text {eff }}(\mathrm{MPa})$} & $1274 \pm 183$ \\
\hline & Quadratic $(\mathrm{k}=2)$ & $0.135 \pm 0.015$ & & $1678 \pm 156$ \\
\hline
\end{tabular}

$\left.\mathrm{HV}_{0.05}\right)$.

Owing to these models, contributions of spinodal decomposition and G-phase particles can be separated. Fig. 4c (for Mobearing) and Fig. 4d (for Mo-free) present these two contributions separately for the two linear superposition principles. Fig. $4 \mathrm{c}$ reveals that G-phase precipitation is the main contributor to hardening of the ferrite of Mo-bearing steels at the beginning of the kinetics. After $2500 \mathrm{~h}$ of ageing, G-phase precipitation represents between $66 \%$ and $77 \%$ of the hardening depending on the models used (Table 5). The G-phase contribution decreases when coarsening of G-phase particles occurs. Only after $8 \times 10^{5} \mathrm{~h}$ of equivalent ageing time at $323^{\circ} \mathrm{C}\left(\sim 100,000 \mathrm{~h}\right.$ at $350^{\circ} \mathrm{C}$, i.e. more than 10 years $)$ does the spinodal decomposition contribution exceed the G-phase one. In the case of Mo-free steels, the number density of G-phase particles is between 5 and 10 time less than in Mo-bearing depending on the ageing time (Fig. 2, Table 3 and $[6,40]$ ). Consequently, G-phase contribution is lower. Thus, the contribution of spinodal decomposition roughly equals the G-phase one (40\% (LAB) and $64 \%$ (LAO)). Nevertheless, it is worth pointing out that the difference between the two models is no more than the experimental uncertainties. It thus seems reasonable to consider a contribution of about $50 \%$ for spinodal and G-phase precipitation at the early stages of ageing for the Mo-free steel. Similarly to the Mobearing steels, the spinodal decomposition contribution starts to overcome the G-phase contribution at about $4 \times 10^{5} \mathrm{~h}$ of equivalent ageing time at $323^{\circ} \mathrm{C}$. 

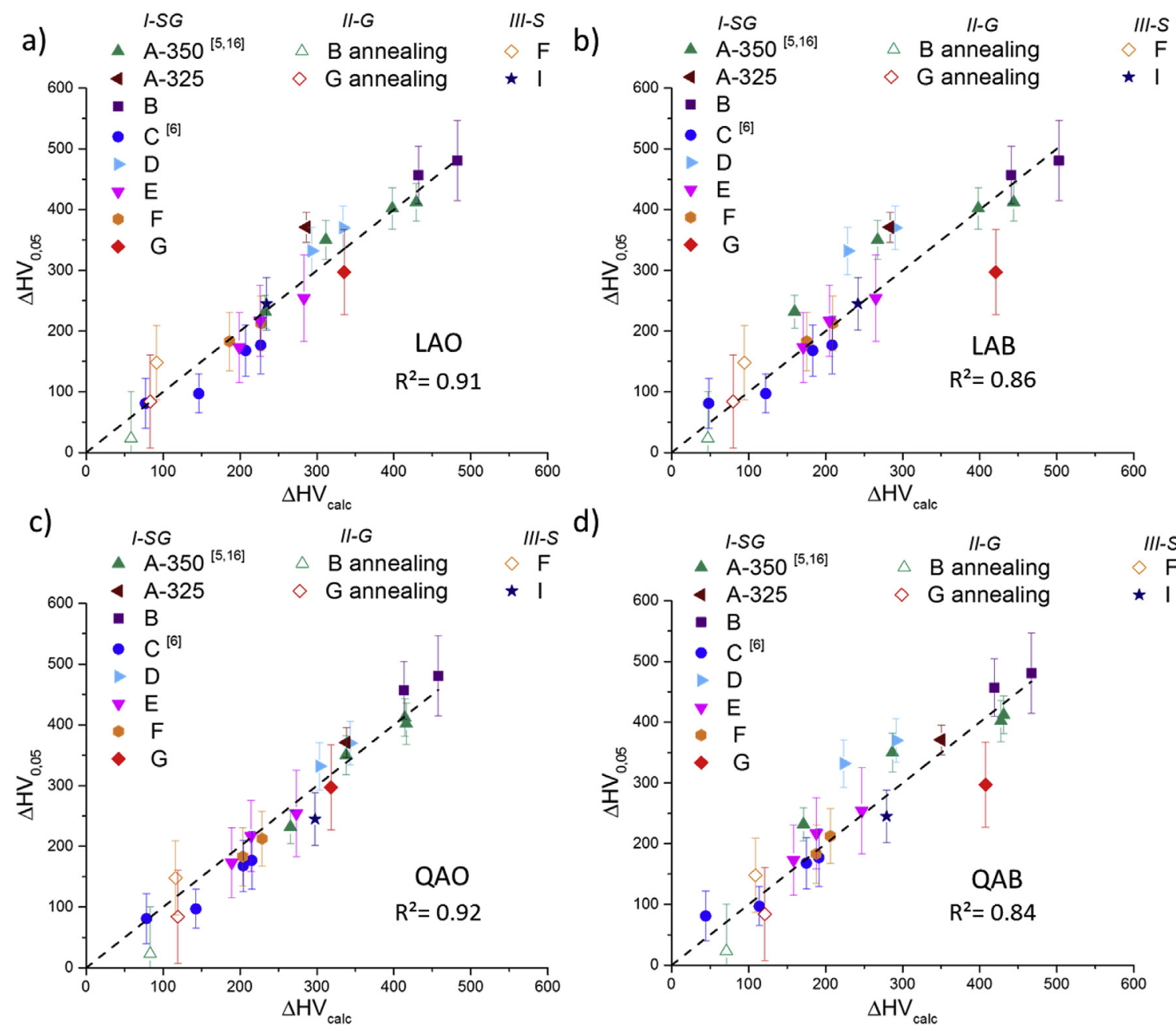

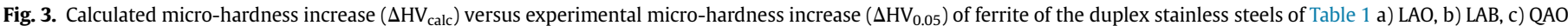
and d) QAB d). The dashed line corresponds to a slope equal to 1 .

These results show that, conversely to what is said in the literature $[3,13,15]$, spinodal decomposition is not systematically the main contributor to hardening. The gap of $150 \mathrm{HV}$ in microhardness increase $\left(\Delta \mathrm{HV}_{0.05}\right)$ between Mo-bearing and Mo-free steels at the beginning of the kinetics is mainly related to Gphase precipitation (Table 5).

With these models, it is also possible to explain the behaviours of alloys $G$ and I. As a reminder, Fig. 1 showed that $G$ and I alloys which are Mo-bearing alloys harden like Mo-free steels. Calculation of the hardness increase based on characteristics of phase separation agrees very well with experimental measurement (Fig. 3). Regarding the results, one can conclude that I alloy hardens less than ferrite of Mo-bearing steels of same composition because of the absence of G-phase precipitation. For alloy G, G-phase particles are present but their number density $\left(\approx 10^{23} \mathrm{~m}^{-3}\right)$ is of the order of magnitude of Mo-free steels i.e. 5-10 times lower than those measured in Mo-bearing steels. Consequently, the micro-hardness is also similar to Mo-free alloy.

The question of the relative contribution of spinodal decomposition and G-phase precipitation is not new. Some authors tried to address the question using reannealing treatments with the goal of dissolving the spinodal decomposed region [3,11,13,15]. Temperatures that were chosen for reannealing were above the miscibility gap between 550 and $650{ }^{\circ} \mathrm{C}$. Chung et al. $[3,14]$ reannealed a Mo free alloy $1 \mathrm{~h}$ at $550^{\circ} \mathrm{C}$. Danoix et al. [13] applied the same reannealing treatment to a Mo-bearing alloy. From their study, Chung et al. $[3,14]$ concluded on the negligible role of G-phase precipitation on hardening of the ferrite. Conversely, Danoix et al. [13] claimed that G-phase precipitation contributed to hardening. These two conclusions seem contradictory. We will show in the following that they are not and we will explain the reasons.

Fig. 5a reports hardness increases before reannealing of the alloys studied by Chung et al. [3,14] and by Danoix et al. [13] together with alloys A-350, B and C [5,6]. The Mo-bearing steel investigated by Danoix et al. [13] behaves similarly to alloys A-350 and B. Similarly, the Mo-free alloy investigated by Chung et al. [3,14] shows hardness increase level of $\mathrm{H}$ Mo-free steel. As neither Chung et al. [3,14] nor Danoix et al. [13] provided the full characteristics of spinodal decomposition and G-phase precipitation, it was not possible to apply the superposition models and calculate the contribution of $\mathrm{G}$-phase precipitation to hardening.

To overcome this problem, we proceeded as follow: Fig. 5b reports the contribution of G-phase precipitation as obtained in the previous part using LAO for both Mo-free and Mo-bearing steels. LAO has been chosen because it gives results with a better $\mathrm{R}^{2}$ value. The graph shows that the logarithm of the percentage of G-phase contribution evolves linearly with the logarithm of the ageing time in the coarsening regime (dotted lines). This is fully coherent with the Lifshitz, Slyosov and Wagner law (LSW) [41,42] which predicts a power law evolution of the number density. Data of Danoix et al. 

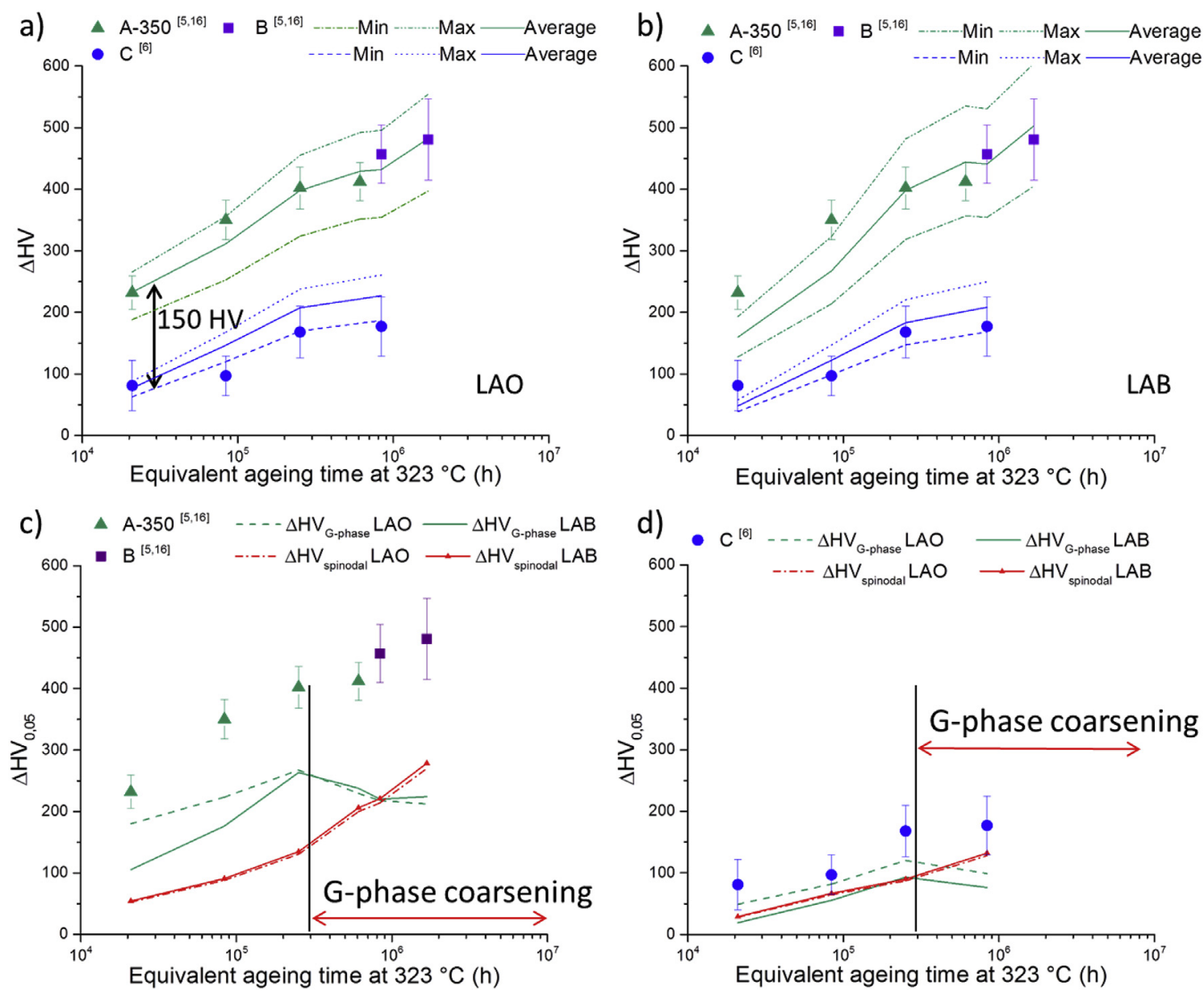

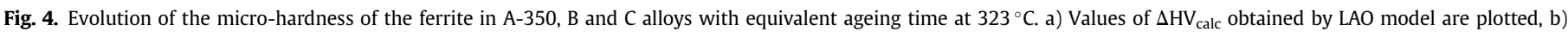

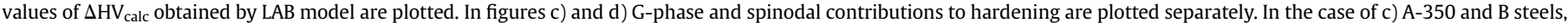
d) C alloy. Also indicated on c) and d), the starting point of G-phase coarsening regime.

Table 5

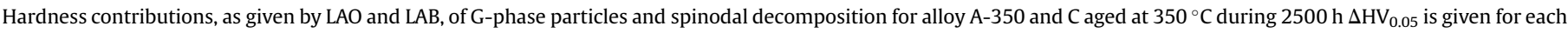
alloys. The hardness difference between the two alloys is given too.

\begin{tabular}{|c|c|c|c|c|c|c|c|}
\hline Linear Model & LAO & & & $\mathrm{LAB}$ & & & Experimental \\
\hline Alloys & $\Delta \mathrm{HV}_{\mathrm{G} \text {-phase }}$ & $\Delta \mathrm{HV}_{\alpha-\alpha^{\prime}}$ & $\Delta \mathrm{HV}_{\text {calc }}$ & $\Delta \mathrm{HV}_{\mathrm{G} \text {-phase }}$ & $\Delta \mathrm{Hv}_{\alpha-\alpha^{\prime}}$ & $\Delta \mathrm{HV}_{\text {calc }}$ & $\Delta \mathrm{HV}_{0.05}$ \\
\hline A-350 & 180 & 53 & 233 & 105 & 54 & 159 & $232 \pm 27$ \\
\hline $\mathrm{C}$ & 49 & 28 & 77 & 19 & 29 & 48 & $82 \pm 41$ \\
\hline Difference between A-350 and C & 131 & 25 & 156 & 86 & 25 & 111 & $150 \pm 68$ \\
\hline
\end{tabular}

[13] were added to the graph regarding two criteria: the equivalent ageing time at $323^{\circ} \mathrm{C}$ and the fact the alloy is Mo-bearing. The equivalent ageing time fix the abscissa. The ordinate is such as the dots must belong to the line related to Mo-bearing steels (green line in Fig. 5b). The same method applied to data of Chung et al. [3,14], but in that case, the dot must belong to the blue dashed line (Mofree alloys) in Fig. 5b.

From Fig. 5b, it is possible to conclude that G-phase contribution represents less than $20 \%$ of the hardening increase before annealing with LAO model for the alloy studied by Chung et al. $[3,14]$. With $\mathrm{LAB}, 15 \%$ is obtained. These results agree well with the conclusion of the authors.

Concerning the alloy studied by Danoix et al. [13], in good agreement with the authors, G-phase has a partial contribution on the hardening with $65 \%$ for the alloy aged for $1000 \mathrm{~h}$ at $400{ }^{\circ} \mathrm{C}, 40 \%$ for $10,000 \mathrm{~h}$ of ageing at $400^{\circ} \mathrm{C}$ and less than $30 \%$ for $30,000 \mathrm{~h}$ of ageing at $400{ }^{\circ} \mathrm{C}$. These authors draw different conclusions because the alloys they studied did not have the same G-phase particle number density/size.

\subsection{Comparison with LEAN alloys}

The model developed in this paper also applies to lean alloys. 2101 and 2205 lean DSS grades behave mechanically as DSS with low Mo content [43-45]. As DSS steels, both spinodal decomposition and G-phase precipitation occur. Guo et al. [12] also proposed a hardening model to evaluate hardening due to G-phase precipitation. Their model is based on the Ashby-Orowan equation [46]. Nevertheless, this model does not take into account the spinodal decomposition contribution. With the aim at describing the evolution of hardness in 2101 and 2205, LAO and LAB models have been applied considering atom probe data obtained by Guo et al. 

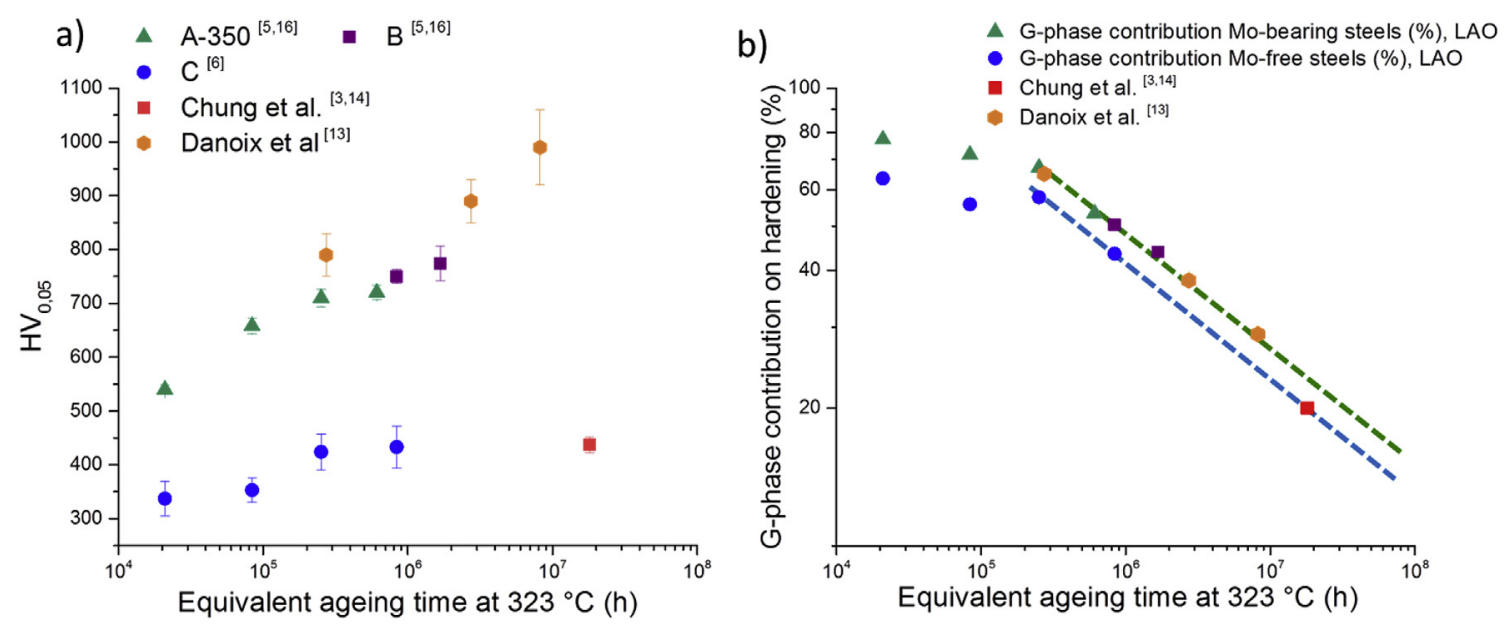

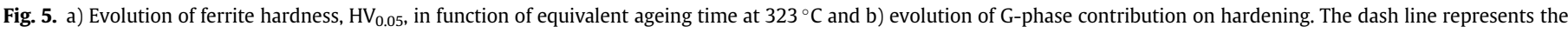

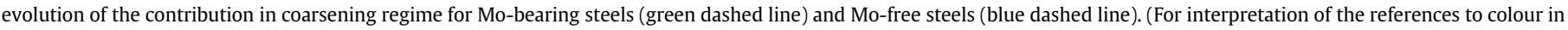
this figure legend, the reader is referred to the Web version of this article.)

Table 6

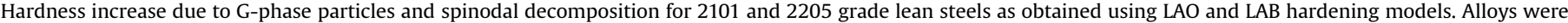
aged at $425^{\circ} \mathrm{C}$. Values estimated by Guo et al. [12] are also reported together with experimental $\Delta \mathrm{Hv}_{\exp }$ values.

\begin{tabular}{|c|c|c|c|c|c|c|c|c|c|}
\hline \multicolumn{2}{|c|}{ Linear Model } & \multicolumn{3}{|l|}{ LAO } & \multicolumn{3}{|l|}{ LAB } & \multirow{2}{*}{$\begin{array}{l}\text { Estimated hardness G-phase by Guo. } \\
\Delta \mathrm{HV}_{\mathrm{G}}\end{array}$} & \multirow{2}{*}{$\begin{array}{l}\text { Experimental } \\
\Delta \mathbf{H V}_{0.05}\end{array}$} \\
\hline Alloys & Ageing time $(\mathrm{h})$ & $\Delta \mathrm{HV}_{\mathrm{G}}$ & $\Delta \mathrm{HV}_{\alpha-\alpha^{\prime}}$ & $\Delta \mathbf{H V}_{\text {calc }}$ & $\Delta \mathrm{HV}_{\mathrm{G}}$ & $\Delta \mathrm{HV}_{\alpha-\alpha^{\prime}}$ & $\Delta \mathbf{H V}_{\text {calc }}$ & & \\
\hline \multirow[t]{3}{*}{2101} & 100 & 10 & 16 & 26 & 5 & 16 & 21 & 3.5 & $17 \pm 8.5$ \\
\hline & 1000 & 36 & 55 & 91 & 26 & 56 & 82 & 32.2 & $79 \pm 13.4$ \\
\hline & 10,000 & 32 & 142 & 174 & 27 & 146 & 173 & 45 & $143 \pm 18$ \\
\hline \multirow[t]{3}{*}{2205} & 100 & 106 & 10 & 116 & 76 & 10 & 86 & 28.0 & $54.4 \pm 11$ \\
\hline & 1000 & 64 & 38 & 102 & 48 & 40 & 88 & 49.0 & $167 \pm 34$ \\
\hline & 10,000 & 86 & 101 & 187 & 78 & 104 & 182 & 75.5 & $233 \pm 72$ \\
\hline
\end{tabular}

[12]. Results are reported in Table 6. They are compared with experimental values of hardness increase and values obtained by Guo et al. [12]. The authors estimated the spinodal decomposition amplitude by two methods: proxigram [47] and LBM (Lager-BaronMiller) method [48]. Micro-hardness increase estimations given in Table 6 were calculated using values obtained from the latter method. Indeed, proxigram values provide micro-hardness increases much too high with respect to experimental ones. The results which are reported in Table 6 are compared with experimental values of hardness increase and values obtained by Guo et al. [12].

Except for 2205 alloy aged $100 \mathrm{~h}$ at $425^{\circ} \mathrm{C}$, the hardness increase due to $\mathrm{G}$-phase particles values agrees well with Guo et al. [12] values. The global hardness increase obtained with LAO and LAB agree reasonably well with experimental values showing the applicability of the models to LEAN alloys except for $100 \mathrm{~h}$ at $425^{\circ} \mathrm{C}$ for grade 2205 for which the total hardness appears overestimated and for $1000 \mathrm{~h}$ (grade 2205) for which hardness is underestimated.

\section{Conclusion}

The aim of this paper was to quantify the relative contribution of spinodal decomposition and G-phase particles on the hardness increase of the ferrite phase in cast duplex stainless steels during thermal ageing. The Ardell [29] model has been considered to account for the hardening of spinodal decomposition. Either the Orowan model or a modified version of BKS model proposed by Monnet $[34,36]$ has been used to take into account hardening due to G-phase precipitation. Linear and square superposition principles have been applied. These models were used to link phase transformation characteristics measured using APT (wavelength and amplitude of spinodal decomposition, size and number density of G-phase particles) with the hardness increase of the ferrite.

The models used have been shown to give an excellent estimation of the experimental values of the hardness increase of the ferrite of the cast steels (Mo-bearing and Mo-free) and lean steels aged in the temperature range $\left[300^{\circ} \mathrm{C}-425^{\circ} \mathrm{C}\right]$.

Among the four models, linear superposition of Ardell and Orowan models gives a slightly better estimation of the experimental values.

This work shows that G-phase precipitation is clearly the main contributor to ferrite hardness increase at early stage of ageing in Mo-bearing steels in the temperature range $\left[323^{\circ} \mathrm{C}-350^{\circ} \mathrm{C}\right]$. In Mofree steels contributions of both spinodal decomposition and Gphase precipitation are similar at early stage of ageing. Conversely to what is said in the literature, spinodal decomposition is not systematically the main contributor to hardening.

The gap of $150 \mathrm{HV}$ in micro-hardness increase between Mobearing and Mo-free steels at early stage of ageing has been shown to be mainly attributed to the G-phase precipitation whose intensity is much higher in Mo-bearing alloys, alloys with more Gphase forming elements.

\section{Acknowledgements}

This work contributes to the research program of the EDF-CNRS joint laboratory EM2VM (Study and Modeling of the Microstructure for Ageing of Materials). This work was carried out owing to experimental GENESIS platform. GENESIS is supported by the Région Haute-Normandie, the Métropole Rouen Normandie, the CNRS via LABEX EMC and the French National Research Agency as a part of the program "Investissements d'avenir" with the 
reference ANR-11-EQPX-0020.

\section{Appendix A. Supplementary data}

Supplementary data to this article can be found online at https://doi.org/10.1016/j.jnucmat.2018.12.002.

\section{References}

[1] P. Auger, F. Danoix, A. Menand, S. Bonnet, J. Bourgoin, M. Guttmann, Atom probe and transmission electron microscopy study of aging of cast duplex stainless steels, Mater. Sci. Technol. 6 (1990) 301-313, https://doi.org/ 10.1179/mst.1990.6.3.301.

[2] H.D. Solomon, L.M. Levinson, Mössbauer effect study of ' $475^{\circ} \mathrm{C}$ embrittlement' of duplex and ferritic stainless steels, Acta Metall. 26 (1978) 429-442, https:/ doi.org/10.1016/0001-6160(78)90169-4.

[3] H. m. Chung, T. r. Leax, Embrittlement of laboratory and reactor aged CF3, CF8, and CF8M duplex stainless steels, in: Mater. Sci. Technol., 1990, pp. 249-262.

[4] F. Danoix, D. Blavette, P. Auger, An atom-probe investigation of some correlated phase transformation in $\mathrm{Cr}$,Ni,Mo containting supersatured ferrite, Surf. Sci. 266 (1992).

[5] C. Pareige, S. Novy, S. Saillet, P. Pareige, Study of phase transformation and mechanical properties evolution of duplex stainless steels after long term thermal ageing (>20 years), J. Nucl. Mater. 411 (2011) 90-96, https://doi.org 10.1016/j.jnucmat.2011.01.036.

[6] C. Pareige, J. Emo, S. Saillet, C. Domain, P. Pareige, Kinetics of G-phase precipitation and spinodal decomposition in very long aged ferrite of a Mo-free duplex stainless steel, J. Nucl. Mater. 465 (2015) 383-389, https://doi.org/ 10.1016/j.jnucmat.2015.06.017.

[7] S. Bonnet, J. Bourgoin, J. Champredonde, D. Guttmann, M. Guttmann, Relationship between evolution of mechanical properties of various cast duplex stainless steels and metallurgical and aging parameters: outline of current EDF programmes, In: Mater. Sci. Technol. (1990) 221-229.

[8] J.J. Shiao, C.H. Tsai, J.J. Kai, J.H. Huang, Aging embrittlement and lattice image analysis in a Fe-Cr-Ni duplex stainless steel aged at $400^{\circ} \mathrm{C}$, J. Nucl. Mater. 217 (1994) 269-278, https://doi.org/10.1016/0022-3115(94)90376-X.

[9] A. Trautwein, Influence of long time aging of CF8 and CF8M cast steel at temperatures between 300 and $500^{\circ} \mathrm{C}$ on the impact toughness and the structure properties, AFS Int. Cast Met. J. 6 (1981) 43-54.

[10] F. Danoix, P. Auger, Atom probe studies of the $\mathrm{Fe}-\mathrm{Cr}$ system and stainless steels aged at intermediate temperature: a review, Mater. Char. 44 (2000) 177-201, https://doi.org/10.1016/S1044-5803(99)00048-0.

[11] J.M. Vitek, S.A. David, D.J. Alexander, J.R. Keiser, R.K. Nanstad, Low temperature aging behavior of type 308 stainless steel weld metal, Acta Metall. Mater. 39 (1991) 503-516, https://doi.org/10.1016/0956-7151(91)90118-K.

[12] W. Guo, D.A. Garfinkel, J.D. Tucker, D. Haley, G.A. Young, J.D. Poplawsky, An atom probe perspective on phase separation and precipitation in duplex stainless steels, Nanotechnology 27 (2016) 254004, https://doi.org/10.1088/ 0957-4484/27/25/254004.

[13] F. Danoix, P. Bas, J.P. Massoud, M. Guttmann, P. Auger, Atom probe and transmission electron microscopy study of reverted duplex stainless steels, Appl. Surf. Sci. 67 (1993) 348-355, https://doi.org/10.1016/0169-4332(93) 90337-B.

[14] H.M. Chung, O.K. Chopra, Kinetics and Mechanism of Thermal Aging Embrittlement of Duplex Stainless Steels, Argonne National Lab., IL (USA), 1987. https://www.osti.gov/scitech/biblio/5856937.

[15] S.L. Li, H.L. Zhang, Y.L. Wang, S.X. Li, K. Zheng, F. Xue, X.T. Wang, Annealing induced recovery of long-term thermal aging embrittlement in a duplex stainless steel, Mater. Sci. Eng. 564 (2013) 85-91, https://doi.org/10.1016 j.msea.2012.11.046

[16] S. Novy, Mécanismes de vieillissement à très longue échéance des aciers inoxydables austénoferritiques, PhD., Rouen, 2009.

[17] J. Brown, An Atom Probe Study of the Spinodal Decomposition in Fe-cr-ni, University of Oxford, Oxford, UK, 1990.

[18] T. r. Leax, S. s. Brenner, J. a Spitznagel, Atom probe examination of thermally aged CF8M cast stainless steel, Metall. Trans. Phys. Metall. Mater. Sci. 23A (1992) 2725-2736.

[19] T.S. Byun, Y. Yang, N.R. Overman, J.T. Busby, Thermal aging phenomena in cast duplex stainless steels, J. Occup. Med. 68 (2016) 507-516, https://doi.org/ 10.1007/s11837-015-1709-9.

[20] B. Gault, M. P.Moody, Atom Probe Microscopy, Springer, Springer, n.d.

[21] W. Lefebvre, F. Vurpillot, X. Sauvage, Atom Probe Tomography: Put Theory into Practice, Academic Press, 2016

[22] M.K. Miller, R.G. Forbes, Atom-probe Tomography: the Local Electrode Atom Probe, Springer US, 2014. http://www.springer.com/gp/book/ 9781489974297. (Accessed 17 July 2018).

[23] M.G. Hetherington, M.K. Miller, Some aspects of the measurement of composition in the atom probe, J. Phys. Colloq. 50 (1989), https://doi.org/ 10.1051/jphyscol:1989892. C8-535-C8-540.

[24] J. Zhou, J. Odqvist, M. Thuvander, P. Hedström, Quantitative evaluation of spinodal decomposition in $\mathrm{Fe}-\mathrm{Cr}$ by atom probe tomography and radial distribution function analysis, Microsc. Microanal. Off. J. Microsc. Soc. Am. Microbeam Anal. Soc. Microsc. Soc. Can. 19 (2013) 665-675, https://doi.org/ 10.1017/S1431927613000470.

[25] J.M. Hyde, G. DaCosta, C. Hatzoglou, H. Weekes, B. Radiguet, P.D. Styman, F. Vurpillot, C. Pareige, A. Etienne, G. Bonny, N. Castin, L. Malerba, P. Pareige, Analysis of radiation damage in light water reactors: comparison of cluster Analysis methods for the analysis of atom probe data, Microsc. Microanal. 23 (2017) 366-375, https://doi.org/10.1017/S1431927616012678.

[26] R. Wagner, Hardening in spinodally decomposed alloys, Czech. J. Phys. B. 31 (1981) 198-208, https://doi.org/10.1007/BF01959443.

[27] M. Kato, Hardening by spinodally modulated structure in b.c.c. alloys, Acta Metall. 29 (1981) 79-87, https://doi.org/10.1016/0001-6160(81)90088-2.

[28] Cahn, Hardening by spinodal decomposition, Acta Metall. 11 (1963) 1275-1282, https://doi.org/10.1016/0001-6160(63)90022-1.

[29] A.J. Ardell, Precipitation hardening, Metall. Trans. A. 16 (1985) 2131-2165, https://doi.org/10.1007/BF02670416.

[30] G. Ghosh, G.B. Olson, The isotropic shear modulus of multicomponent Fe-base solid solutions, Acta Mater. 50 (2002) 2655-2675, https://doi.org/10.1016/ S1359-6454(02)00096-4.

[31] F. Bergner, C. Pareige, M. Hernández-Mayoral, L. Malerba, C. Heintze, Application of a three-feature dispersed-barrier hardening model to neutronirradiated Fe-Cr model alloys, J. Nucl. Mater. 448 (2014) 96-102, https:// doi.org/10.1016/j.jnucmat.2014.01.024.

[32] H. Bakker, H.P. Bonzel, C.M. Bruff, M.A. Dayananda, W. Gust, J. Horvath, I. Kaur, G.V. Kidson, A.D. LeClaire, H. Mehrer, G.E. Murch, G. Neumann, N. Stolica, N.A. Stolwijk, Diffusion in Solid Metals and Alloys/Diffusion in festen Metallen und Legierungen, Springer-Verlag, Berlin Heidelberg, 1990. http://www. springer.com/us/book/9783540508861.

[33] A. Mateo, L. Llanes, M. Anglada, A. Redjaimia, G. Metauer, Characterization of the intermetallic G-phase in an AISI 329 duplex stainless steel, J. Mater. Sci. 32 (1997) 4533-4540, https://doi.org/10.1023/A:1018669217124.

[34] A.K. Seeger, On the theory of radiation damage and radiation hardening, in: Proc 2nd UN Int Conf Peac. Uses At. Energy, 6, 1959.

[35] D.J. Bacon, U.F. Kocks, R.O. Scattergood, The effect of dislocation selfinteraction on the orowan stress, Philos. Mag. 28 (1973) 1241-1263, https://doi.org/10.1080/14786437308227997.

[36] G. Monnet, Multiscale modeling of precipitation hardening: application to the Fe-Cr alloys, Acta Mater. 95 (2015) 302-311, https://doi.org/10.1016/ j.actamat.2015.05.043.

[37] S. Queyreau, G. Monnet, B. Devincre, Orowan strengthening and forest hardening superposition examined by dislocation dynamics simulations, Acta Mater. 58 (2010) 5586-5595, https://doi.org/10.1016/j.actamat.2010.06.028.

[38] J.M. Rosenberg, H.R. Piehler, Calculation of the taylor factor and lattice rotations for bcc metals deforming by pencil glide, Metall. Trans. 2 (1971) 257-259, https://doi.org/10.1007/BF02662666.

[39] E.J. Pavlina, C.J.V. Tyne, Correlation of yield strength and tensile strength with hardness for steels, J. Mater. Eng. Perform. 17 (2008) 888-893, https://doi.org/ $10.1007 /$ s11665-008-9225-5.

[40] J. Emo, Etude expérimentale et par simulation Monte Carlo des transformations de phase dans la ferrite des aciers austéno-ferritiques et de leurs alliages modèles, Rouen, 2014.

[41] I.M. Lifshitz, V.V. Slyozov, The kinetics of precipitation from supersaturated solid solutions, J. Phys. Chem. Solid. 19 (1961) 35-50, https://doi.org/10.1016/ 0022-3697(61)90054-3.

[42] C.Z. Wagner, Z. Elektrochem, Theory of precipitate change by redissolution, Phys. Chem. 65 (1961) 581-591.

[43] J.-Y. Maetz, S. Cazottes, C. Verdu, F. Danoix, X. Kléber, Microstructural evolution in 2101 lean duplex stainless steel during low- and intermediatetemperature aging, Microsc. Microanal. 22 (2016) 463-473, https://doi.org/ $10.1017 /$ S1431927616000167.

[44] D.A. Garfinkel, J.D. Poplawsky, W. Guo, G.A. Young, J.D. Tucker, Influence of alloying on $\alpha-\alpha^{\prime}$ phase separation in duplex stainless steels, in: Proc. 18th Int Conf. Environ. Degrad. Mater. Nucl. Power Syst. - Water React., Springer, Cham, 2018, pp. 1183-1192, https://doi.org/10.1007/978-3-319-68454-3_85.

[45] J.D. Tucker, M.K. Miller, G.A. Young, Assessment of thermal embrittlement in duplex stainless steels 2003 and 2205 for nuclear power applications, Acta Mater. 87 (2015) 15-24, https://doi.org/10.1016/j.actamat.2014.12.012.

[46] T. Gladman, Precipitation hardening in metals, Mater. Sci. Technol. 15 (1999) 30-36, https://doi.org/10.1179/026708399773002782.

[47] O.C. Hellman, J. Vandenbroucke, J. Rüsing, D. Isheim, D. Seidman, Analysis of three-dimensional atom-probe data by the proximity histogram, Microsc. Microanal. Off. J. Microsc. Soc. Am. Microbeam Anal. Soc. Microsc. Soc. Can. 6 (2000) 437-444, https://doi.org/10.1007/s100050010051.

[48] J. Langer, M. Bar-On, H. d. Miller, New computational method in the theory of spinodal decomposition, Phys. Rev. Gen. Phys. 11 (1975) 1417-1429. 